\title{
Невматулина К.A.
}

\section{ПРИОРИТЕТЫ РАЗВИТИЯ}

\section{СПЕЦИАЛЬНЫХ ЭКОНОМИЧЕСКИХ ЗОН РЕСПУБЛИКИ КАЗАХСТАН}

Невматулина Карина Анваровна, заместитель директора Центра международнъх программ и проектов Карагандинского экономического университета, доктор экономических наук

Карагандинский экономический университет Казпотребсоюза, ул. Академическая, 9, Караганда, 100009, Республика Казахстан

E-mail:carisha_o7@mail.ru

\section{Аннотация}

$3^{a}$ а весь период становления и развития специальньх экономических зон (далее - СЭЗ) в Республике Казахстан вся правовая основа их деятельности модернизировалась не менее четырех раз, было принято множество подзаконных и нормативно-правовых актов. Совершенствовались также и организационно-экономический и финансовый механизмы деятельности СЭ3. Многократная реформа законодательства, регламентирующего создание и работу СЭ3, оказала стимулирующее воздействие на производство, позволила интегрировать товары на внутреннем рынке, а также обеспечить дополнительные рабочие места. Следующим шагом в развитии СЭЗ в Казахстане является создание на территории страны экономических зон кластерного типа. Симбиоз возможностей кластерной политики и положений законодательства Республики Казахстан о специальных экономических зонах станет мощным катализатором индустриально-инновационного развития страны. В свою очередь, создание кластеров в рамках уже существующих специальных экономических зон позволит наполнить их качественными проектами, способными создавать экспортоориентированную продукцию.

K диверсификация экономики. 


\section{PRIORITIES OF DEVELOPMENT}

Nevmatulina K.A.

\section{OF SPECIAL ECONOMIC ZONES OF THE REPUBLIC OF KAZAKHSTAN}

Nevmatulina Karina Anvarovna, Deputy Director of the Center for International Programs and Projects Department of Economy and Management, $P h D$ in Economics

Karaganda Economic University of Kazpotrebsoyuz 9, Academicheskaya St., Karaganda, 100009, Kazakhstan

E-mail: carisha_07@mail.ru

\section{A}

uring the entire period of formation and development of special economic zones (further-SEZ) in the Republic of Kazakhstan, all the legal basis of their activity was modernized no less than four times, a number of subordinate and normative legal acts were accepted. The organizational, economic and financial mechanisms of SEZ activity were improved. A repeated reform of the legislation regulating creation and work of SEZ has made a stimulating impact on production, allowed to integrate goods into domestic market, and also to provide additional workplaces. The next step in the development of SEZ in Kazakhstan is the creation of economic zones of cluster type on the territory of the country. A symbiosis of opportunities of cluster policy and provisions of the legislation of the Republic of Kazakhstan on special economic zones will make a powerful impact on the industrial and innovative development of the country. Further, the creation of clusters within the already existing special economic zones will allow to fill them with high-quality projects capable of creating export-oriented production.

Keywords: special economic zone; cluster; competitiveness; diversification of economy. 
Введение. Сформированный в Государственной программе по форсированному индустриально-инновационному развитию (далее - ГП ФИИР) Республики Казахстан вектор развития специальных экономических зон, связанный с развитием преимуществ географического положения и природных зон страны, может и должен совершенствоваться в дальнейшем. В ходе реализации первого этапа ГП ФИИР 2010-2014 гт. [2] удалось осуществить «перезагрузку» казахстанских СЭЗ и вывести их на качественно новый этап развития. На сегодняшний день назрела объективная необходимость определения новых векторов и приоритетов развития рассматриваемого рода экономических отношений.

Основная часть. Одним из приоритетов развития специальных экономических зон в Казахстане является повышение эффективности применения концепции специальных экономических зон, связанное не только с совершенствованием функционирования в стране уже действующих специальных экономических зон, но также с формированием их качественно новых моделей и форм.

Для реализации указанных задач была разработана и утверждена Постановлением Правительства Республики Казахстан от 31 декабря 2013 года № 1497 Концепция индустриально-инновационного развития Республики Казахстан на 2015-2019 годы [9], так называемая «вторая пятилетка» ГП ФИИР. В рамках данной Концепции предусматривается сбалансированная поддержка трех групп отраслевых секторов, обеспечивающая достижение цели и выполнение задач ГП ФИИР и создающая предпосылки для разумной диверсификации экономики:

1) базовые секторы;

2) рыночно-ориентированные секторы;

3) инновационные секторы.

Первая группа отраслевых секторов - базовые секторы - представляет собой отрасли производства товаров, непосредственно связанные с переработкой ресурсов и крупнотоннажным производством промышленных товаров.

Вторая группа отраслевых секторов - рыночно-ориентированные сектора - представляет собой все отрасли промышленности, движимые спросом на внутреннем рынке и имеющие существенные возможности для развития за счет увеличения присутствия на рынках макрорегиона.

Третья группа отраслевьх секторов - инновационные сектора - представляет собой все сектора так называемой «новой экономики», развитие которых во многом определяется результатами научных исследований и разработок, в том числе информационно-коммуникационные и космические технологии, биотехнологии, технологии новых материалов и возобновляемых источников энергии.

Формирование экономических кластеров в рамках каждого из перечисленных секторов является одним из наиболее действенных методов обеспечения выполнения указанных выше задач, как на локальном уровне, так и на уровне всей страны. Как было отмечено в Послании Президента Н.А. Назарбаева народу страны Стратегия «Казахстан-2050»: новый политический курс состоявшегося государства» от 14 декабря 2012 г. [8] ключевым инструментом реализации Стратегии «Казахстан-2050" должен стать именно кластерный подход. С учетом этого Главой государства поставлены следующие задачи: определить модели кластерного развития; разработать «дорожные карты» по формированию перспективных национальных кластеров; разработать Концепцию формирования перспективных национальных кластеров.

На сегодняшний день целью кластерного развития для нашей страны является обеспечение высоких темпов экономического роста, диверсификации и модернизации национальной экономики за счет повышения конкурентоспособности отечественных предприятий, кооперации науки и бизнеса, поставщиков, комплектующих, специализированных производственных и сервисных услуг, научно-исследовательских и образовательных организаций, образующих перспективные национальные кластеры.

Для реализации данной цели, в рамках первой группы отраслевых секторов приоритетными являются следующие кластеры:

1) металлургический кластер. В Карагандинской области представлены предприятия добывающей и перерабатывающей промышленности, научно-исследовательские 
центры и профильные учебные заведения. Именно в этом секторе наиболее целесообразно формирование приоритетного конкурентоспособного кластера. Это открывает хорошую перспективу в кратчайшие сроки повысить коммерческое использование мощного металлургического комплекса Карагандинской области. Вокруг этих предприятий сконцентрировано более 300 поставщиков оборудования и материалов, необходимњх для их деятельности;

2) нефтехимический кластер. Этот кластер может оказать стимулирующее воздействие на предприятия машиностроения, металлообработки, судостроительный и транспортный комплексы. Серьезньх технологических решений потребуют технологии отбора, транспортировки, сжижения и переработки природного газа, которые создадут предпосылки для формирования новых инновационных кластеров. В этой связи, целесообразно создать пилотные проекты в Атырауской и Павлодарской областях.

В рамках второй группы отраслевых секторов - рыночно-ориентированные секторы - целесообразно сформировать текстильно-промышленшый кластер в Южно-Казахстанской области. Текстильная и легкая промышленность - одна из основнњх отраслей экономики, формирующих бюджет во многих странах мира. В Казахстане имеется растущее производство хлопка, который в болышом объеме экспортируется. Существуют также швейные компании, способные производить различную продукцию, как для внутреннего, так и для внешнего рынка.

К третьей группе отраслевьх секторов - инновационные секторы - можно отнести формирование интеллектуально-инновационного кластера. Приоритетными в этой деятельности являются компьютерные технологии и программы, ядерные технологии, космос и телекоммуникации, медицина и фармацевтика, энергоэффективность, а также другие высокотехнологические направления. В сеть интеллектуально-инновационного кластера должны входить индустриальная площадка, где будут располагаться высокотехнологичные производства, отраслевые институты национальных компаний, исследовательские центры казахстанских и зарубежных компаний, а так- же элементы инновационной инфраструктуры: технопарк, бизнес-инкубатор, центр коммерциализации и трансферта технологий, инновационный венчурный фонд [10].

В целях успешного формирования и развития различного рода кластеров необходим правильный выбор места расположения и размещения кластерньх инициатив. В этом вопросе особую практическую значимость приобретает СЭ3. Как было отмечено ранее, СЭЗ - это часть национального экономического пространства, где для отечественных и зарубежных предпринимателей создается система льгот и стимулов, которая на основе новейших технологий позволяет создавать приоритетные отрасли экономики, способные, в свою очередь, обеспечить производство и поставку высококачественной продукции на мировой рынок. Учитывая это, в Казахстане кластеры целесообразно формировать в рамках уже существующих специальньх экономических зонах, позволив им получить право на серийное производство разработанной наукоемкой продукции.

В этой связи, по нашему мнению, в рамках реализации и ГП ФИИР и Стратегии «Казахстан - 2050» в Казахстане целесообразно создать кластеры в рамках уже существующих специальных экономических зон:

1) нефтехимический кластер на базе СЭЗ «Павлодар» и/или СЭЗ «Национальный индустриальный нефтехимический технопарк»;

2) металлургический кластер на базе СЭЗ «Сары Арка»;

3) текстильно-промьшленный кластер на базе СЭЗ «Онтустык»;

4) инновационный кластер на базе СЭЗ «Паркинновационных технологий» уже создан Законом «Об инновационном кластере «Парк инновационных технологий» от 10 июня 2014 года № 207-V ЗРК [5].

Создание подобных структур предполагает объединение положений законодательства Республики Казахстан о специальньх экономических зонах, а также задач и возможностей кластерной политики и становится катализатором и условием формирования специальных экономических зон кластерного типа.

Специальная экономическая зона кластерного типа будет представлять особую форму специальных экономических зон, формируемую для реализации полного цикла выпуска 
готовой продукщии (главным образом, создание подобньх зон должно быть ориентировано на высокотехнологичные отрасли), разделенную на несколько кластерных секторов (рис.).
Представляется необходимњп применять дифференцированный подход к формированию экономических преференций и разного рода льгот в рамках такого образования [7].

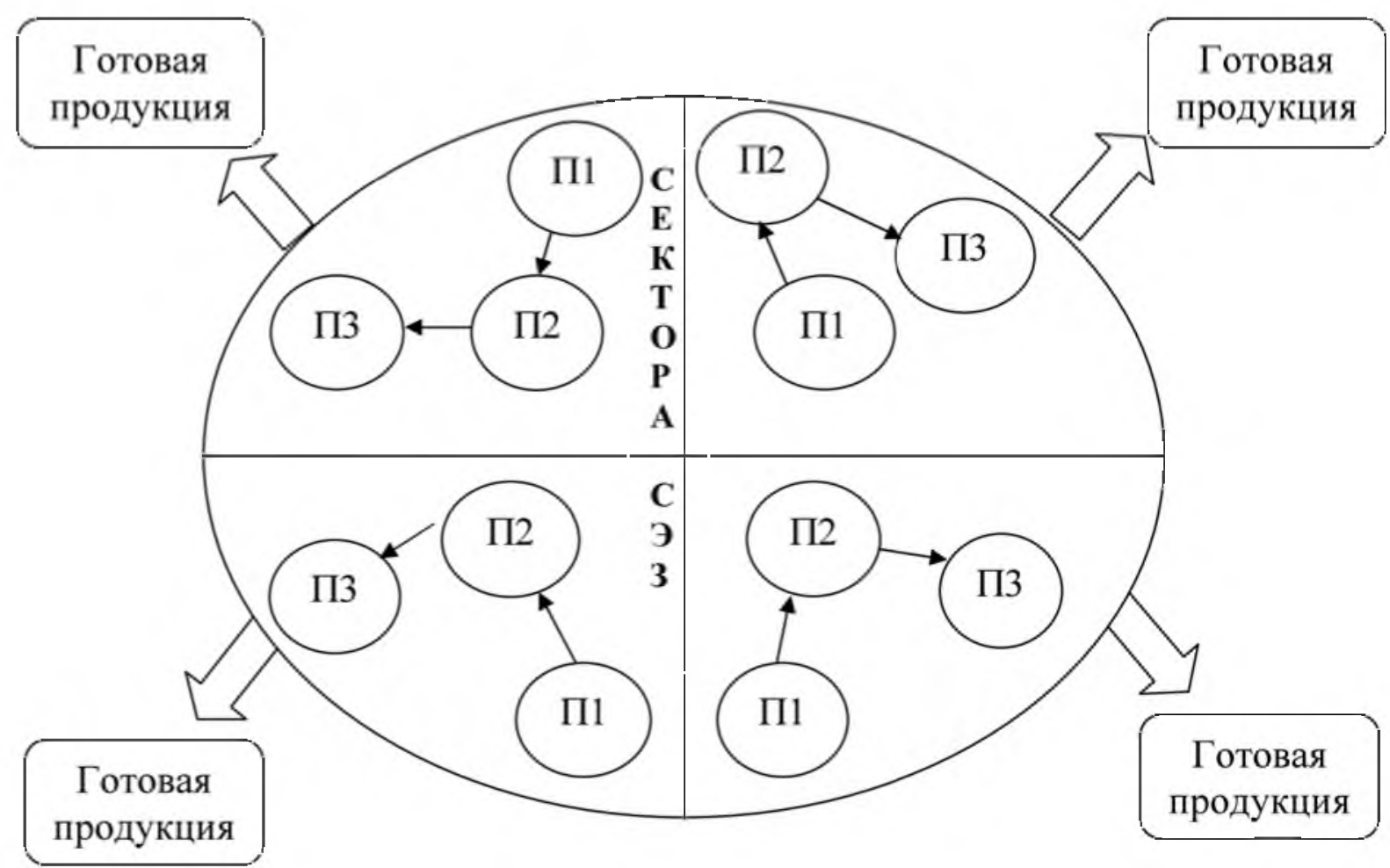

Рис. Система взаимосвязей в СЭЗ кластерного типа

Fig. System of interrelations in SEZ of cluster type

Процесс формирования специальньх экономических зон кластерного типа в Республике Казахстан должен учитывать следующие ключевые моменты:

1) зона такого типа разделяется на несколько сегментов (кластерньх) для развития территории, в рамках которой создается такая форма экономических отношений. Необходимость этого связана с возможностью обеспечения разнонаправленного развития территории, на которой базируется кластер и соседствующих областей, а также позволит снизить уровень потенциальньх рисков;

2) реализация индивидуального подхода к распределению экономических преференций в рамках кластерных специальных экономических зон необходима для активизации различных сфер деятельности в рамках кластера, в зависимости от их приоритетности, что может быть обусловлено спецификой того или иного этапа развития экономики или кластера.

Эффективная реализация идеи создания кластерньх специальных экономических зон позволит при наличии должньх объемов финансирования сформировать в республике полноценные наукоемкие производства, а также увеличить конкурентоспособность казахстанских производственньх предприятий и продукции на мировых рынках.

Изучение опыта развитых стран показывает, что СЭЗ кластерного типа обладают рядом преимуществ [3]:

1) в отличие от традиционных промышленных предприятий, кластеры представляют собой систему тесных взаимосвязей не только между фирмами реального сектора, их поставщиками и потребителями, но и институтами знаний, среди которых исследовательские центры, вузы, НИИ. При этом в процесс включаются поставщики и потребители, а также предприятия других отраслей и в результате межфирменной кооперации уменьшаются издержки на НИОКР;

2) субъекты фирмы - участники кластера, особенно малого и среднего бизнеса, способны 
более адекватно и быстрее реагировать на потребности покупателей;

3) кластерные структуры создают положительные эффекты не только для самого кластерного объединения и его участников, но и для регионов базирования: увеличение занятости, рост заработной платы и прибыли, интенсификация предпринимательской активности и т.д.;

4) возможность координации усилий и финансовых средств для создания нового продукта и технологий и выхода с ними на рынок. В рамках кластера становится возможным выстраивание технологической цепочки от создания продукта до его производства и вывода на рынок;

5) создание в рамках кластеров преимущественно экспортно-ориентированной продукции и технологий, т.е. внутрикластерные конкурентные преимущества оказываются значимыми в международном масштабе;

6) участие государства в формировании кластерных стратегий;

7) наличие в системе кластеров гибких предпринимательских структур - малых предприятий, конкурирующих в процессе производства креативных идей, позволяющих нащупывать инновационные точки роста экономики региона;

8) региональные и локальные кластеры обеспечивают мальп фирмам высокую степень специализации при обслуживании конкретной предпринимательской ниши, поскольку обеспечивается доступ к капиталу промышленного предприятия, прочим ресурсам, а также активно происходит обмен идеями и передача знаний от ученьх к предпринимателям;

9) преимуществом кластера также является эффект охвата, возникающий при существовании фактора производства, который может быть использован одновременно для производства нескольких видов продукции. Помимо этого, структура кластера способствует снижению совокупных затрат на исследование и разработку новшеств за счет повьшения эффекта.

Кластеры способствуют развитию региональных и национальных экономик, что обусловлено следующими особенностями [1]:

- взаимосвязи внутри кластера ведут к появлению новых методов конкуренции;

- кластеры создают условия для формирования региональных инновационных систем;

- для всей экономики страны или реги- она кластеры выполняют роль «точек роста» внутреннего рынка и освоения международного. Наличие целого кластера отраслей ускоряет процесс создания факторов конкурентных преимуществ за счет совместных инвестиций в развитие технологий, в информацию, инфраструктуру, образование;

- взаимосвязи внутри кластера обеспечивают развитие аутсорсинга, когда малые и средние предприятия производят продукцию, работы и услуги для ключевых субъектов кластера, тем самым способствуют развитию бизнеса в регионе;

- конкуренция между производителями в кластере приводит к углублению специализации, поиску новых ниш и расширению кластера, в результате чего образуются новые субъекты бизнеса, что повышает доходность регионального производства, решает проблемы занятости населения и усиливает интеграционный потенциал региона;

- кластеры являются одной из институциональных форм обеспечения приграничного сотрудничества в сфере торговли, сельского хозяйства, туризма, транспорта, инфраструктуры, что способствует экономическому развитию приграничных территорий.

Так, интерес Казахстана к созданию приграничного кластера на границе с Туркменистаном, прежде всего, диктуется строительством железной дороги Узень - Гызылгая - Берекет - Этрек - Горган с последующим выходом к морским портам Ирана с учетом дальнейшей перспективы передачи в аренду на 99 лет портов в Аравийском море. Этим проектом заинтересован и Казахстан. Кроме того, ведется подготовка проекта строительства нефтепровода Казахстан - Туркменистан - Иран.

Безусловно, создание приграничного кластера на границе с Туркменистаном идея хорошая, но все же необходимо взвесить все «за» и «против». Прежде всего, выбрать удобную территорию с уже развитой инфраструктурой, достаточным количеством профессионалов для его управления, конкретными льготами и преференциями, определить функщию кластера.

Существует и проблема иного характера: насколько будет заинтересован в создании зоны приграничного сотрудничества Туркменистан. Во-первых, туркменский рынок очень невелик, бизнес здесь не развит, а возможности туркменских бизнесменов ограничены только торговыми сделками. Во-вторых, Туркмени- 
стан уже пробовал на своей территории создавать подобные организационные формы, в том числе на границе с Ираном - итог нулевой.

Западные инвесторы не хотят вести дела на границе со страной, по отношению к которой постоянно вводятся экономические санкции, а стабильность в регионе ее расположения очень шатка. В-третьих, иранский бизнес в основном сосредоточен в центре и на юге страны. Все деловые контакты осуществляются со странами Персидского залива и через Турцию. В-четвертых, несмотря на многолетние заверения официального Ашхабата, Туркменистан, к сожалению, все еще остается закрытой страной [6] .

Однако следует отметить, что наряду с преимуществами кластерного развития для региональной и национальной экономик, государство также приобретает и ряд ключевьх проблем при формировании и реализации государственной политики кластерного развития:

1. Недостаточность усилий региональньх властей по улучшению условий для успешной и эффективной кластеризации;

2. Недостаточная эффективность инструментов государственной поддержки: ограниченная гибкость, неразвитость механизмов распределения рисков между государством и бизнесом, слабая ориентированность на стимулирование связей между различными участниками инновационньх процессов, на формирование и развитие научно-производственных кластеров;

3. Сохранение барьеров для распространения в экономике новых технологий, обусловленных отраслевым регулированием, процедурами сертификации, таможенным и налоговым администрированием;

4. Низкая экономическая активность промышленньх предприятий республики. При этом основными экономическими факторами, сдерживающими активность предприятий реального сектора экономики являются низкий инновационный потенциал, недостаток собственньх средств для расширения деятельности, высокая стоимость нововведений, экономические риски и длительные сроки окупаемости;

5. Взаимодействие науки, бизнеса и государства в формировании и реализации кластерной политики пока не носит достаточно регулярного характера, не обеспечивает сбалансированного представления интересов различньх предприятий;
6. Низкая информационная прозрачность бизнес-среды. Это, прежде всего, недостаток информации о новых технологиях и возможных рынках сбыта принципиально нового продукта, а также сведений для частньх инвесторов и кредитных организаций об объектах вложения капитала с потенциально высокой доходностью;

1. Практическое отсутствие анализа передовых технологий в мире и возможностей их использования в Республике Казахстан. Отсутствие научно обоснованной системы долгосрочного технологического планирования и др.

Для эффективного осуществления кластерной политики требуется создание адекватной системы мониторинга и оценки реализации кластерных инициатив. Важным условием функционирования систем мониторинга должна быть их непрерывность, т.е. возможность в реальном времени отслеживать рост и барьеры, препятствующие развитию кластеров [4].

Заклочение. Таким образом, с целью эффективной реализации принятых государственньх программ на современном этапе развития Республики Казахстан формирование экономических кластеров является действенным способом обеспечения повьшения конкурентоспособности, как на локальном уровне, так и на уровне государства. Объединение положений законодательства Республики Казахстан о специальньх экономических зонах с задачами и возможностями кластерной политики является катализатором и условием формирования специальньх экономических зон кластерного типа. Специальная экономическая зона кластерного типа будет представлять особую, в какой-то мере принципиально новую форму специальньх экономических зон, формируемую для реализации полного цикла выпуска готовой продукщии, разделенную на несколько кластерньх секторов. Учитывая направления индустриально-инновационной политики в Казахстане, целесообразно и экономически обосновано будет формирование специальньг экономических зон кластерного типа в рамках наиболее значимьх существующих специальных экономических зон. 


\section{СПИСОК ЛИТЕРАТУРЫ}

1. Баженова Ю.В. Мировой опыт применения кластерного подхода в развитии свободных экономических зон и российские перспективы: Дис. ... к-та. эк. наук. М., 2009. 156 с.

2. Государственная программа по форсированному индустриально-инновационному развитию Республики Казахстан на 2010-2014 годы: утв. Указом Президента Республики Казахстан 19 марта 2010 года, № 958. URL: http://baiterek. gov.kz/ru/gov-programs/gpfiir-program (дата обращения 29.09.2013).

3. Cluster Analysis \& Cluster-based policy in OECD-countries various approaches, earl results \& policy implications / Ed. by Theo J. A. Roelandt, Pim den Hertog. // Report by the Focus Group on: Industrial clusters. 1999. URL: http://www.oecd. org/daf/corporate.

4. Еспаев С.С. Концепция формирования и развития перспективных национальных кластеров: монография. Алматы, 2013. 233 с.

5. Закон Республики Казахстан «Об инновационном кластере «Парк инновационных технологий», 10 июня 2014 года, № 207-V ЗРК.

6. Информация о ходе реализации Конвенции о приграничном сотрудничестве государств - участников Содружества Независи- мых Государств, 15 марта 2013 года, г. Москва URL: http://e-cis.info/page.php?id=23408 (дата обращения 25.04.2014).

7. Невматулина К.А. Пути совершенствования специальных экономических зон в Республике Казахстан: Дис. ... д-ра философии (PhD). Караганда, 2014. 154 c.

8. Послание Президента Республики Казахстан - Лидера нации Н. Назарбаева народу Казахстана «Стратегия «Казахстан-2050»: новый политический курс состоявшегося государства» от 14 декабря 2012 года. URL: http://www. akorda.kz/ru/page/page_poslanie-prezidentarespubliki-kazakhstan-lidera-natsii-nursultananazarbaeva-narodu-kazakhstana (дата обращения 25.04.2013).

9. Постановление Правительства Республики Казахстан. Об утверждении Концепции индустриально-инновационного развития Республики Казахстан на 2015-2019 годы, 31 декабря 2013 года, № 1497.

10. Указ Президента Республики Казахстан. Об утверждении Концепции инновационного развития Республики Казахстан до 2020 года, 4 июня 2013 года, № 579.

\section{REFERENCES}

1. Bazhenova Yu.V. World Experience of Application of a Cluster Approach in the Development of Free Economic Zones and Russian Prospects: Dis. ... c-te. ec. sciences. M., 2009. 156 p.

2. The State Program on Forced Industrial and Innovative Development of the Republic of Kazakhstan for 2010-2014: approved by the Decree of the President of the Republic of Kazakhstan on March 19, 2010, No. 958. URL: http://baiterek .gov. $\mathrm{kz} / \mathrm{ru}$ /gov-programs/gpfiir-program (date of access September 29, 2013).

3. Cluster Analysis \& Cluster-based Policy in OECDcountries various approaches, earl results \& policy implications/Ed. by Theo J. A. Roelandt, Pim den Hertog.//Report by the Focus Group on: Industrial clusters - 1999. - URL: http://www.oecd.org/daf/ corporate (date of viewing 25.03.2014).

4. Espayev S. S. The Concept of Formation and Development of Perspective National Chusters: Monograph. Almaty, 2013. 233 p.

5. The Law of the Republic of Kazakhstan «On the Innovative Chuster «The Park of Innovative Technologies», June 10, 2014, No. 207-V ZRK.

6. Information on the Course of Implementation of the Convention on Border Cooperation of the State Parties of the Commonwealth of Independent
States, March 15, 2013, Moscow. URL: http://e-cis. info/page.php? id=23408 (date of access April 25, 2014).

7. Nevmatulina K. A. Ways of Improvement of Special Economic zones in the Republic of Kazakhstan: Dis.... Dr. of Philosophy (PhD). Karaganda, 2014. $154 \mathrm{p}$.

8. The Message of the President of the Republic of Kazakhstan - the Leader of the Nation N. Nazarbayev to the People of Kazakhstan «The Strategy «Kazakhstan-2050»: a New Political Policy of the Formed State», December 14, 2012. URL: $\quad$ http://www.akorda.kz/ru/page/page_ poslanie-prezidenta-respubliki-kazakhstan-lideranatsii-nursultana-nazarbaeva-narodu-kazakhstana (date of access April 25, 2013).

9. The Resolution of the Government of the Republic of Kazakhstan. On the Approval of the Concept of Industrial and Inmovative Development of the Republic of Kazakhstan for 2015-2019. December 31, 2013, No. 1497.

10. The Decree of the President of the Republic of Kazakhstan. On the approval of the Concept of Innovative Development of the Republic of Kazakhstan until 2020, June 4, 2013, No. 579. 